\section{Powdery Mildew Resistance in the U.S. National Plant Germplasm System Cucumber Collection}

\author{
Charles C. Block ${ }^{1}$ \\ Agricultural Research Service, U.S. Department of Agriculture, North Central \\ Regional Plant Introduction Station, Ames, IA 50011
}

\begin{abstract}
Kathleen R. Reitsma
Iowa State University, North Central Regional Plant Introduction Station, Ames, IA 50011
\end{abstract}

Additional index words. Sphaerotheca fuliginea, Erysiphe cichoracearum, Cucumis sativus, plant germplasm, disease resistance

\begin{abstract}
Nine hundred and seventy-seven (977) cucumber (Cucumis sativus L.) accessions from the U.S. National Plant Germplasm System (NPGS) collection were tested for resistance to powdery mildew, caused by the fungus Podosphaera xanthii (Castagne) Braun and Shishkoff, formerly known as Sphaerotheca fuliginea (Schlecht.) Poll. Plants from each accession were evaluated in the greenhouse following inoculation with field isolates of $P$. xanthii. Each plant was placed into one of three susceptibility classes based on the amount of fungal growth and sporulation on the hypocotyl, stem, petioles and leaves - susceptible $(S)$, intermediate (I) or resistant (R). Of the 977 accessions $(9.6 \%), 94$ contained at least one I or R-type plant. Seventeen of the 20 most-resistant accessions came from Asian sources, including China (PIs 418962, 418964, 432860, and 432870), India (PIs 197085, 197088, and 605930), Japan (PIs 279465, 288238, 390258, and 390266), Pakistan (PI 330628), the Philippines (PIs 426169 and 426170), and Taiwan (PIs 321006, 321009, and 321011). A quantitative study was conducted to compare mildew reproduction on S, I, and R-type cucumbers in the greenhouse and under field conditions in Ames, Iowa. Leaf disks were removed weekly and microscopic counts made of spore populations. The leaf disk method was superior to visual rating for ranking and differentiating intermediate from resistant accessions. Both the intermediate (moderately resistant) and highly resistant accessions provided excellent protection against powdery mildew in the field.
\end{abstract}

Powdery mildew is one of the world's most widespread and damaging diseases of greenhouse and field-grown cucumbers (Cucumis sativus L.). The most frequently cited causal agents are Golovinomyces cichoracearum Gelyuta (syn. Erysiphe cichoracearum DC) and Podosphaera xanthii (Castagne) Braun and Shishkoff (syn. Sphaerotheca fuliginea (Schlecht.) Poll.). In early reports (Barnes and Epps, 1956; Whitaker and Davis, 1962), G. cichoracearum was identified as the primary causal agent in the United States, but more recent studies indicate that $P$. xanthii is the more common pathogen in the U.S. (Ballantyne, 1975; McCreight et al., 1987). Both species were observed on Cucumis melo L. in France, with P. xanthii isolated alone in $79 \%$ of the cases, G. cichoracearum isolated alone in $18 \%$ of the cases, and the remainder a mixture of both fungi (Pitrat et al., 1998). The primary causal agent in the U.S. may have shifted toward P. xanthii over time, but there were probablemisidentifications in some of the older literature. The two species can be difficult to differentiate in the absence of the perfect stage, but useful identification

Received for publication 27 May 2004. Accepted for publication 19 Aug. 2004. We thank Mark Widrlechner, Thomas Gulya and Candice Gardner for helpful suggestions during the preparation of this manuscript.

${ }^{1}$ Author to whom correspondence should be addressed; e-mail ccblock@iastate.edu. known about the extent of powdery mildew resistance present in the collection. Therefore, the objectives of this study were 1) to screen a large number of accessions from the NPGS collection for powdery mildew reaction, 2) to identify the most resistant accessions, and 3) to compare powdery mildew spore production on susceptible, intermediate, and resistant cucumbers under greenhouse and field conditions.

\section{Materials and Methods}

Greenhouse evaluation procedures. In total, 977 accessions from the cucumber germplasm collection held at the North Central Regional Plant Introduction Station (NCRPIS) at Ames, Iowa, were evaluated for powdery mildew resistance. The initial screening was conducted on cucumber Plant introductions (PIs) in a winter greenhouse by evaluating one replication of 10 plants per accession. The cucumbers were grown in $38 \times 53 \times 9 \mathrm{~cm}$ rectangular metal flats containing five accessions planted in single rows, with 10 plants per row. A susceptible check cultivar, 'National Pickling', was planted in every second flat and a moderately resistant check variety (intermediate-type reaction), either 'Galaxy' or 'Poinsett', was planted in every fifth flat. Evaluations were conducted at a room temperature of $25^{\circ} \mathrm{C}$ day and $22{ }^{\circ} \mathrm{C}$ night with a 12 -h photoperiod.

Accessions that were 100\% susceptible were not evaluated again. Accessions containing one or more plants with an intermediate or resistant reaction were retested one to four additional times. The evaluations spanned the period from 1987-2002, with new accessions added as seed became available. About 780 accessions were screened in 1987-88. In 1995, any resistant accessions from 1987-88 were retested along with about 120 newly available accessions. In 2001, 85 newly available accessions were evaluated, and then in 2002, all accessions showing any level of resistance in previous evaluations were obtained and tested. Different field-collected isolates of $P$. xanthii were used in 1987-88, in 1995 , and in 2001-02. Thus, all of the accessions subjected to retests were exposed to two or three unique $P$. xanthii isolates. Repeated testing of individual accessions with different isolates provided a good assessment of the reliability or reproducibility of the data.

Inoculum preparation and application. The $P$. xanthii isolates were maintained on young plants of the cultivar 'National Pickling' throughout the winter. To obtain spores for inoculation, several heavily infected leaves were soaked in deionized water with Tween 20 surfactant added at $0.02 \%$ (about 4 drops $/ \mathrm{L}$ ). The suspension was filtered through two layers of cheesecloth and spore concentration was adjusted to 50,000 to $75,000 / \mathrm{mL}$. The suspension was applied to cucumber seedlings using a 1-L hand sprayer. Plants were inoculated three times, first when the cotyledons were fully expanded and twice more at 3 to $4 \mathrm{~d}$ intervals. Inoculations were made in the late afternoon, but no special precautions were taken other than turning off the air circulation fans overnight and spraying the concrete floor with water to increase humidity. 
Disease ratings. The first signs of infection usually appeared as small, faintly visible mildew colonies 3 to $4 \mathrm{~d}$ after inoculation. Disease was well developed after 11 to $12 \mathrm{~d}$ and leaves and stems of susceptible accessions were normally covered with mildew mycelia and spores by this time. Diseasereaction was recorded on individual plants of each PI at 18 and $21 \mathrm{~d}$ after the first inoculation. Ratings were based on hypocotyl, stem, petiole and leaf reactions following a three part rating scale based on that described by Shanmugasundaram et al. (1971), where susceptible (S) indicated that development was unrestricted; cotyledons, stems, both sides of the leaves, hypocotyls and petioles were covered with mildew mycelia and spores. Intermediate or moderately resistant (I) indicated that stems, petioles, and hypocotyls were clean; leaves had visiblemildew development over the entire upper leaf surface and sporulation ranged from mild to heavy. Resistant $(\mathrm{R})$ indicated that stems, petioles, and hypocotyls were clean; mildew colony development and sporulation on leaves was highly restricted with no visible mildew or only a faint film of visible mycelium. Both the intermediate and resistant reaction types identify potentially useful germplasm. Theintermediate reactiontype corresponds to moderately resistant germplasm while the resistant reaction type corresponds to highly resistant germplasm.

Quantitative study of powderymildew spore production. Asubset of eight accessions and two cultivars were selected for a quantitative study of powdery mildew spore production. The main goal of the study was to determine if spore counts would be an improvement over visual ratings for differentiating intermediate from resistant accessions. Entries were selected to represent a range of disease reactions from susceptible through resistant. Two entries were considered to be $100 \%$ susceptible ('Marketer' and 'Ashley'), three contained predominantly ( $>75 \%$ ) intermediate plants (PIs 234517, 432895, and 451976), and five contained predominantly $(>90 \%)$ resistant plants (PIs 197088, 288238, 321006, 390258 , and 426170). None of the PIs from the intermediate or resistant groups contained any susceptible plants except for PI 432895, with 2\% susceptible plants, and PI 288238, with 9\%. PI 288238 ('Yomaki plant II') was included in the resistant group for this study because Clark

Table 1. Geographic origin and powdery mildew resistance reactions of individual plant introductions (PIs).

\begin{tabular}{|c|c|c|c|c|}
\hline Geographic region/country & $\begin{array}{l}\text { No. of PIs } \\
\text { evaluated }\end{array}$ & $\begin{array}{l}\text { No. of PIs with } \\
\text { resistant plants } \\
\text { (I or R reactions) }\end{array}$ & $\begin{array}{l}\text { PIs with only I and/or R } \\
\text { plant reactions } \\
\text { and } \% \text { of plants of each type }\end{array}$ & $\begin{array}{l}\text { PIs with susceptible (S) plants } \\
\text { along with I and/or R plants } \\
\text { and } \% \text { of plants of each type }\end{array}$ \\
\hline \multicolumn{5}{|l|}{ Africa } \\
\hline Egypt (via Japan) & 22 & 1 & & $288238(9 \% \mathrm{~S}, 91 \% \mathrm{R})$ (via Japan) \\
\hline Ethiopia & 2 & 0 & & \\
\hline Kenya & 1 & 1 & & $385967(13 \% \mathrm{~S}, 2 \% \mathrm{I}, 85 \% \mathrm{R})$ \\
\hline Zimbabwe & 1 & 0 & & \\
\hline \multicolumn{5}{|l|}{ Asia } \\
\hline \multicolumn{5}{|l|}{ North } \\
\hline Georgia & 2 & 0 & & \\
\hline Russia & 45 & 2 & & $\begin{array}{l}435946(32 \% \mathrm{~S}, 68 \% \mathrm{I}) \\
435947(9 \% \mathrm{~S}, 43 \% \mathrm{I}, 48 \% \mathrm{R})\end{array}$ \\
\hline Uzbekistan & 6 & 0 & & \\
\hline \multicolumn{5}{|l|}{ Middle East } \\
\hline Afghanistan & 15 & 0 & & \\
\hline Iran & 62 & 0 & & \\
\hline Iraq & 1 & 0 & & \\
\hline Israel & 9 & 0 & & \\
\hline Lebanon & 4 & 0 & & \\
\hline Oman & 3 & 0 & & \\
\hline Syria & 12 & 0 & & \\
\hline Turkey & 172 & 0 & & \\
\hline \multicolumn{5}{|l|}{ Central, south, and east } \\
\hline Bhutan & 6 & 0 & & \\
\hline \multirow[t]{21}{*}{ China } & 113 & 41 & $418962(20 \% \mathrm{I}, 80 \% \mathrm{R})$ & $105340(64 \% \mathrm{~S}, 36 \% \mathrm{I})$ \\
\hline & & & $418964(100 \% \mathrm{R})$ & $391570(12 \% \mathrm{~S}, 88 \% \mathrm{I})$ \\
\hline & & & $432850(100 \% \mathrm{I})$ & $418963(7 \% \mathrm{~S}, 44 \% \mathrm{I}, 49 \% \mathrm{R})$ \\
\hline & & & $432859(100 \% \mathrm{I})$ & $432860(8 \% \mathrm{~S}, 27 \% \mathrm{I}, 65 \% \mathrm{R})$ \\
\hline & & & $432862(65 \% \mathrm{I}, 35 \% \mathrm{R})$ & $432868(8 \% \mathrm{~S}, 50 \% \mathrm{I}, 42 \% \mathrm{R})$ \\
\hline & & & $432870(100 \% \mathrm{R})$ & $432869(8 \% \mathrm{~S}, 92 \% \mathrm{I})$ \\
\hline & & & 432874 (67\%I, 33\%R) & $432873(6 \% \mathrm{~S}, 81 \% \mathrm{I}, 13 \% \mathrm{R})$ \\
\hline & & & $432875(100 \% \mathrm{I})$ & $432889(55 \% \mathrm{~S}, 45 \% \mathrm{I})$ \\
\hline & & & $432876(100 \% \mathrm{I})$ & $432890(22 \% \mathrm{~S}, 78 \% \mathrm{I})$ \\
\hline & & & $432877(78 \% \mathrm{I}, 22 \% \mathrm{R})$ & $432891(20 \% \mathrm{~S}, 80 \% \mathrm{I})$ \\
\hline & & & $432878(100 \% \mathrm{I})$ & $432892(24 \% \mathrm{~S}, 76 \% \mathrm{I})$ \\
\hline & & & $432879(100 \% \mathrm{I})$ & $432893(46 \% \mathrm{~S}, 54 \% \mathrm{I})$ \\
\hline & & & $432880(95 \% \mathrm{I}, 5 \% \mathrm{R})$ & $432894(53 \% \mathrm{~S}, 47 \% \mathrm{I})$ \\
\hline & & & $432881(94 \% \mathrm{I}, 6 \% \mathrm{R})$ & $432895(2 \% \mathrm{~S}, 91 \% \mathrm{I}, 7 \% \mathrm{R})$ \\
\hline & & & 432882 (91\%I, 9\%R) & $432896(30 \% \mathrm{~S}, 70 \% \mathrm{I})$ \\
\hline & & & $432883(100 \% \mathrm{I})$ & $432897(21 \% \mathrm{~S}, 79 \% \mathrm{I})$ \\
\hline & & & $432884(100 \% \mathrm{I})$ & $436608(22 \% \mathrm{~S}, 56 \% \mathrm{I}, 22 \% \mathrm{R})$ \\
\hline & & & $432885(100 \% \mathrm{I})$ & $478365(50 \% \mathrm{~S}, 50 \% \mathrm{I})$ \\
\hline & & & $432886(100 \% \mathrm{I})$ & $489752(13 \% \mathrm{~S}, 58 \% \mathrm{I}, 29 \% \mathrm{R})$ \\
\hline & & & $483342(58 \% \mathrm{I}, 42 \% \mathrm{R})$ & $518849(40 \% \mathrm{~S}, 60 \% \mathrm{I})$ \\
\hline & & & $518853(30 \% \mathrm{~S}, 70 \% \mathrm{I})$ & \\
\hline \multirow[t]{3}{*}{ Hong Kong } & 4 & 3 & & $267742(74 \% \mathrm{~S}, 26 \% \mathrm{R})$ \\
\hline & & & & $267743(42 \% \mathrm{~S}, 25 \% \mathrm{I}, 33 \% \mathrm{R})$ \\
\hline & & & & $419214(9 \% \mathrm{~S}, 49 \% \mathrm{I}, 42 \% \mathrm{R})$ \\
\hline \multirow[t]{7}{*}{ India } & 132 & 13 & $197088(100 \% R)$ & $197085(30 \% \mathrm{~S}, 17 \% \mathrm{I}, 53 \% \mathrm{R})$ \\
\hline & & & 605929 (93\%I, 7\%R) & $197086(26 \% \mathrm{~S}, 33 \% \mathrm{I}, 41 \% \mathrm{R})$ \\
\hline & & & $605930(48 \% \mathrm{I}, 52 \% \mathrm{R})$ & $197087(50 \% \mathrm{~S}, 43 \% \mathrm{I}, 7 \% \mathrm{R})$ \\
\hline & & & $605932(100 \% \mathrm{I})$ & $262974(60 \% \mathrm{~S}, 30 \% \mathrm{I}, 10 \% \mathrm{R})$ \\
\hline & & & $605933(100 \% \mathrm{I})$ & $605916(64 \% \mathrm{~S}, 36 \% \mathrm{I})$ \\
\hline & & & $606048(100 \% \mathrm{I})$ & $605924(72 \% \mathrm{~S}, 28 \% \mathrm{I})$ \\
\hline & & & $504569(90 \% \mathrm{~S}, 10 \% \mathrm{I})$ & \\
\hline
\end{tabular}


(1975) reported it as the most resistant line in previous Iowa tests and because of its historical value as a source of mildew resistance (Jahn et al., 2002; Munger, 1988). The few susceptible plants found in PI 432895 and PI 288238 were discarded before leaf sampling began. All accessions were grown in the same metal flats used for the preliminary screening, with one accession of 50 plants in each flat. Flats were arranged in a randomized complete block design with four replications. Plants were inoculated as previously described. Leaves were sampled at 1-week intervals, beginning $19 \mathrm{~d}$ after the first inoculation, and continuing for 3 weeks. On each sampling date, 15 leaves were collected per flat and two disks were punched from each leaf with a $12 \mathrm{~mm}$ diameter cork borer (1.13 $\mathrm{cm}^{2}$ ). Mildew sporulation occurred mainly on the upper leaf surface, and therefore only the upper surface was used to calculate the total leaf area represented by the 30 disks $\left(33.9 \mathrm{~cm}^{2}\right)$. The 30 disks were placed in a $125-\mathrm{mL}$ erlenmeyer flask containing $20 \mathrm{~mL}$ of deionized water plus Tween 20 at 2 drops/L. Flasks were placed on a reciprocating shaker at $150-175 \mathrm{rpm}$ for 25 to $30 \mathrm{~min}$. After removal from the shaker, spore counts were made using a hemacytometer counting chamber. Spore counts were converted to spores $/ \mathrm{mL}$ of water and then to the spores per $\mathrm{cm}^{2}$ of leaf tissue.

The spore production study was carried out twice in the greenhouse and once in the field. Field plots consisted of $5 \mathrm{~m}$ long rows, containing about 20 plants per row, with four replicates arranged in a randomized complete block design. Field plots were inoculated, sampled, and processed in the manner described for the greenhouse. Because disease development progressed very slowly in the field, the initial sampling was delayed until mid-August, 38 days after the first inoculation. Samples were collected at weekly intervals for five weeks.

Analyses of variance were performed on the spore count data using PC-SAS version 8.02 (SAS Institute, Cary, N.C.). Data from the two greenhouse $(\mathrm{GH})$ tests were pooled for analysis after meeting an $F$ test for homogeneity of error variances (Gomez and Gomez, 1984). Separate analyses were done for the 19-d and 26-d counts. The 33-d GH data were not used to evaluate differences among PIs because spore counts either remained static when compared to the 26-d counts or declined due to leaf senescence. Because disease development was so slow in the field, only the week five data (peak spore counts) were used in the analysis of variance. For all of the data analyses, treatment means (PIs) were compared using the Waller-Duncan least significant difference test.

\section{Results and Discussion}

Greenhouse evaluations of cucumber accessions. In the greenhouse tests, 94 of the 977 accessions $(9.6 \%)$ contained at least one plant that showed an intermediate (I) or high (R) level of powdery mildew (P.xanthii) resistance (Table 1). Of the 94 PIs, 41 contained plants with only resistant(Ior R)reactions(Table 1). Theresponses of the other 53 PIs were more heterogeneous, meaning that some combination of susceptible plants was found along with intermediate and/or

Table 1 (continued). Geographic origin and powdery mildew resistance reactions of individual plant introductions (PIs).

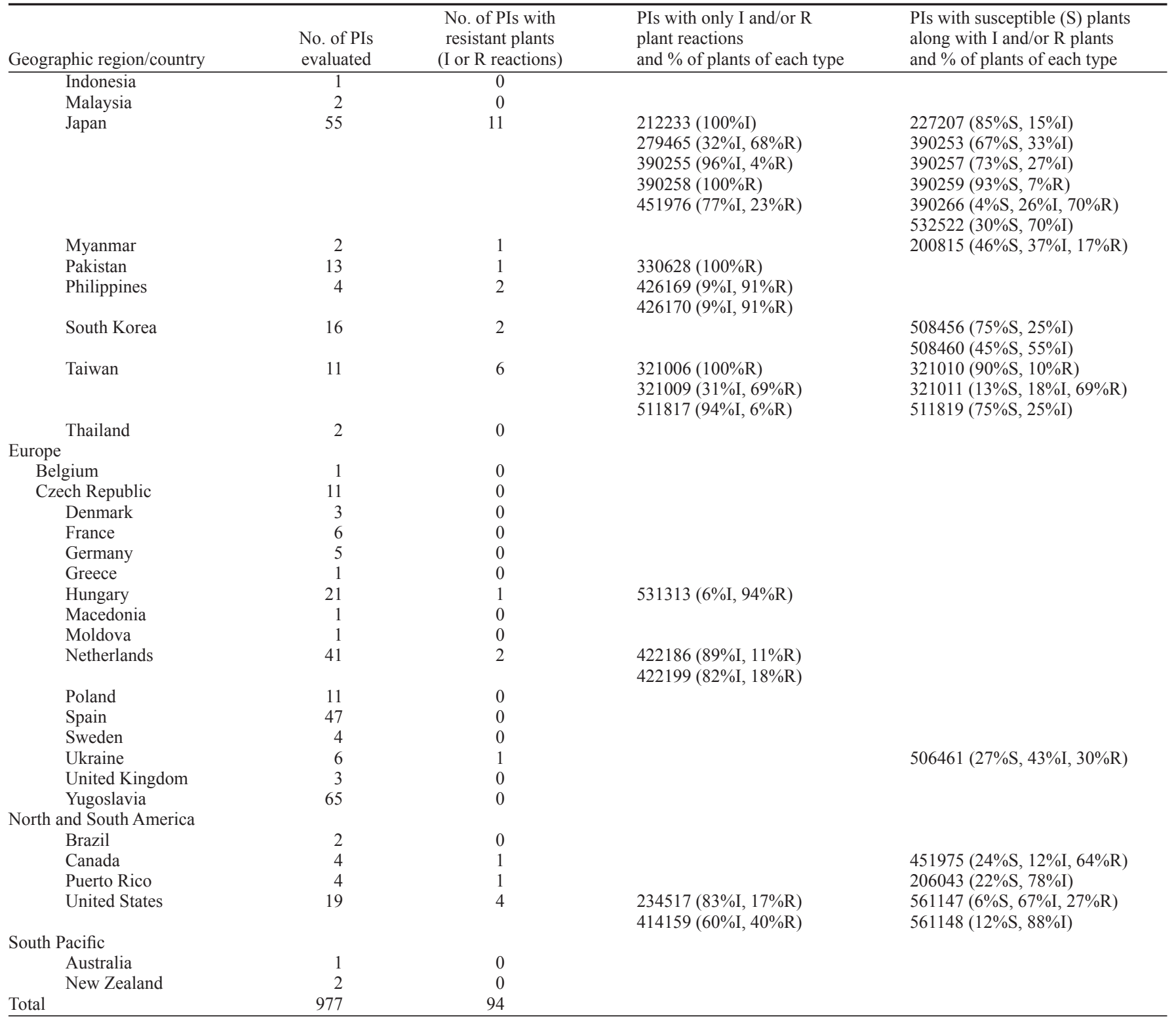


Table 2. Powdery mildew (Podosphaera xanthii) spore counts from leaf disk assays of greenhouse-grown (GH) and field-grown plants

\begin{tabular}{|c|c|c|c|c|c|c|}
\hline Entry & Source & $\begin{array}{l}\text { Local } \\
\text { name }\end{array}$ & $\begin{array}{l}\text { Visual } \\
\text { rating }\end{array}$ & $\begin{array}{c}19-\mathrm{d} \mathrm{GH} \\
\text { count }^{\mathrm{z}}(\times 1000)\end{array}$ & $\begin{array}{c}26-\mathrm{d} \text { GH } \\
\text { count }(\times 1000)\end{array}$ & $\begin{array}{c}\text { 67-d Field } \\
\text { count }(\times 1000)\end{array}$ \\
\hline Ashley & U.S. & Ashley & $100 \% \mathrm{~S}$ & $55.2 \mathrm{a}$ & $94.3 \mathrm{a}$ & $15.8 \mathrm{ab}$ \\
\hline Marketer & U.S. & Marketer & $100 \% \mathrm{~S}$ & $41.8 \mathrm{~b}$ & $91.2 \mathrm{a}$ & $18.6 \mathrm{a}$ \\
\hline PI 451976 & Japan & Yomaki & $77 \%$ I, 23\% R & $30.7 \mathrm{c}$ & $64.5 \mathrm{~b}$ & $13.0 \mathrm{bc}$ \\
\hline PI 432895 & China & Si 3928 & $2 \% \mathrm{~S}, 91 \% \mathrm{I}, 7 \% \mathrm{R}$ & $28.4 \mathrm{c}$ & $40.9 \mathrm{c}$ & $6.4 \mathrm{de}$ \\
\hline PI 234517 & U.S. & SC-50 & $83 \% \mathrm{I}, 17 \% \mathrm{R}$ & $27.3 \mathrm{c}$ & $32.3 \mathrm{~cd}$ & $9.3 \mathrm{~cd}$ \\
\hline PI 426170 & Philippines & UPL-Cu-2 & $9 \% \mathrm{I}, 91 \% \mathrm{R}$ & $19.3 \mathrm{~d}$ & $32.8 \mathrm{~cd}$ & $8.6 \mathrm{~cd}$ \\
\hline PI 197088 & India & --- & $100 \% \mathrm{R}$ & $5.7 \mathrm{e}$ & $10.5 \mathrm{ef}$ & $0.8 \mathrm{f}$ \\
\hline PI 321006 & Taiwan & Fengyuan Green Skin & $100 \% \mathrm{R}$ & $3.1 \mathrm{e}$ & $20.2 \mathrm{de}$ & $1.3 \mathrm{ef}$ \\
\hline PI 288238 & Egypt (Japan) & Yomaki plant II & $9 \% \mathrm{~S}, 91 \% \mathrm{R}$ & $2.2 \mathrm{e}$ & $16.4 \mathrm{ef}$ & $0.5 \mathrm{f}$ \\
\hline PI 390258 & Japan & Sado Risshu & $100 \% \mathrm{R}$ & $1.3 \mathrm{e}$ & $5.0 \mathrm{f}$ & $0.2 \mathrm{f}$ \\
\hline
\end{tabular}

${ }^{\mathrm{z}}$ Spore populations measured in conidia recovered per square centimeter of cucumber leaf. The study was carried out twice in the greenhouse (GH) and once in the field. Means separations were made by Waller-Duncan test; $\mathrm{k}$ ratio $=100, P \leq 0.05$ (lowercase letters).

resistant plants (Table 1). A search of passport information on the GRIN database at http://www. ars-grin.gov/npgs showed that some of the segregating accessions were originally donated to the NPGS collection as hybrid cucumber cultivars. Others originated as fruits collected in vegetable markets or as open-pollinated varieties obtained from local seed dealers. Cucumber seed production at NCRPIS is done in screened cages using insect pollinators (Clark et al., 1991). Segregation for powdery mildew resistance would be expected if the original germplasm samples were heterozygous for genes conferring resistance to powdery mildew.

There was a notable absence of resistance in some of the larger germplasm groups, such as accessions from Turkey ( 0 of 172), the former nation of Yugoslavia (0 of 65), Iran (0 of 62) and Spain (0 of 47) (Table 1). We found no resistance among 278 accessions tested from Middle Eastern countries and only four resistant (includes I and R-types) accessions among 227 tested from European countries. Of the 94 PIs with intermediate or resistant plants, only eight were not directly traceable to southern or eastern Asia. The countries of China, India, and Japan were particularly well represented with 41,13 , and 11 resistant accessions, respectively. The eight exceptions were PI 422186 ('Numerus') and PI 422199 ('Witlo') from the Netherlands, PI531313 ('Kecskemeti Livme') from Hungary, PI 506461 ('Parad 176') from the Ukraine, PI 435946 ('Konkurent') and PI 435947 ('Parad') from Russia, PI 414159 ('Lehau No. 1') from Hawaii, and PI 385967 ('Cool and Crisp') from Kenya. The original source of the resistance in these accessions was probably from introduced germplasm, as none of these accessions could be considered a traditional landrace, but likely resulted from intentional breeding and selection.

Cultivated cucumber (C. sativus) is indigenous to India, having been domesticated there for at least 3,000 years (Leppik, 1966; Whitaker and Davis, 1962) with China considered as a secondary center for diversity (Leppik, 1966; Walters, 1989). Cucumber breeders in western Europe and North America have long used germplasm from China, Japan, India, and other Asian countries in powdery mildew resistance breeding (Barnes and Epps, 1956; Kooistra, 1968; Zijlstra and Groot, 1992). For example, Kooistra (1968) crossed the mildew-resistant Japanese cultivar 'Natsufushinari' with the less resistant PI 200815 from Myanmar, and found a few plants that were superior in resistance to either parent. 'Natsufushinari' is maintained in the NPGS collection as PI 279465 and showed excellent resistance in our evaluations with $32 \%$ I and $68 \%$ R-type plants. PI 200815 contained a mixture of $46 \%$ susceptible, $37 \%$ intermediate, and $17 \%$ resistant plants in our evaluations (Table 1).

Four U.S. accessions were classified as having some level of mildew resistance, PI 234517 ('SC-50'), PI414159 ('Lehau No. 1'), PI 561147 ('Spartan Salad') and PI 561148 ('Marketmore 76 '). The source of the powdery mildew resistance in PI 414159 is not documented in GRIN, but the resistance genes for the other three are traced to India and Japan. PI234517 was derived from a backcross of ('Ashley' $\times$ PI 197087) $\times$ 'Ashley' (Barnes and Epps, 1956). PI 197087 was collected in 1951 from Assam, India and had $50 \%$ susceptible, $43 \%$ intermediate, and $7 \%$ resistant plants in our tests. The Japanese accession PI 212233 was the source of powdery mildew resistance in developing 'Spartan Salad' (Jahn et al., 2002). 'Spartan Salad' was then used as the powdery mildew resistance source for 'Marketmore 76' (Munger et al., 1979). PI 212233 was rated as $100 \%$ intermediate in our tests (Table 1), consistent with the results of Shanmugasundaram et al. (1971), who concluded that PI 212233 had a major recessive gene $s$ that conferred hypocotyl resistance, but lacked a dominant gene $R$ for leaf resistance. Leaf resistance $R$ was only expressed in the presence of hypocotyl resistance. Jahn et al. (2002) recently suggested that the linked gene for powdery mildew resistance be referred to as $p m-s$ instead of $s$.

Highly powdery mildew-resistant accessions. Twenty accessions were considered highly powdery mildew-resistant, defined in this study as containing $50 \%$ or more R-type plants (Table 1). Eighteen of the 20 accessions were easily traced to Asian backgrounds, the exceptions being PI 531313 (Hungary) and PI 385967 (Kenya). Six accessions had 100\% R-type plants, PI 197088 from India, PI 321006 from Taiwan, PI330628 from Pakistan, PI390258 from Japan, and PIs 418964 and 432870 from China.

Usefulness of the S-I-R disease rating method. The S-I-R rating method was effective for identifying powdery mildew resistant accessions, but was not useful for sorting resistance, from higher to lower, within the large group of accessions that clustered in the intermediate category. With the S-I-R scale, both intermediate and resistant plants have clean hypocotyls and petioles, but the intermediate plants have more mildew visible on the leaves. When sporulation was moderate to heavy in the greenhouse, plants were relatively easy to classify as susceptible, intermediate, or resistant. When sporulation was lighter, the distinction between intermediate and resistant types was less obvious. We did not observe the resistant reaction type described by Shanmugasundaram et al. (1971), where only one to two colonies per leaf, or only chlorotic spots were found. The most resistant accessions in our studies had a faint, but uniform film of mycelium overmuch of their upper leaf surfaces. The difference in the type of resistant $(\mathrm{R})$ reaction observed in this study may have been due to inoculation method. Shanmugasundaram et al. (1971) inoculated plants by dusting dry conidia onto them, whereas the spray used in this study likely distributed inoculum more uniformly and may have increased the inoculum dose per square centimeter of leaf area.

There was an interesting series of Chinese accessions from PI 432868 through PI 432897 , as 26 of these 30 PIs contained resistant (I or R-type) plants (Table 1). Eight of the accessions consistently had every plant rate in the intermediate category. In the other 18 resistant accessions, however, there were perceptible differences in sporulation among plants within accessions. These accessions contained mixtures of susceptible and intermediate (S and I) plant types, mixtures of intermediate and resistant (I and $\mathrm{R}$ ) plant types, or mixtures of all three (S, I and R) plant types.

Quantitative study of mildew spore counts. The five accessions chosen as the resistant group for the quantitative study (PIs 197088, $288238,321006,390258$, and 426170) showed no significant differences among them at the 19-d GH count or during the field study, except for PI 426170. PI 426170 fell between the resistant and intermediate groups at the 19-d GH count, clustered with the intermediate accessions at the 26-d GH count, and was intermediate in the field test (Table 2). PI 426170 had 9\% intermediate plants in the original visual evaluations, the only accession in the resistant group that contained any intermediate plants. Based on the sporulation data, the resistance in PI 426170 would probably be more accurately classified as intermediate rather than highly resistant.

Three of the other four accessions in the resistant group performed significantly better than the intermediate and susceptible entries at every 
counting date. The exception was PI 321006, which ranked in the middle of the resistant group at the 19-d GH count, but fell to the bottom of that group and overlapped one of the accessions from the intermediate group at both the 26-d count and in the field study (Table 2). Because spore counts were so low in the field study, this observation was not thought to be of practical importance for cucumber production.

PI451976('Yomaki') was the least resistant of the intermediate accessions (PI 234517, PI 432895, and PI 451976), based on the 26-d GH counts and the field counts. After $26 \mathrm{~d}$, PI 451976 had significantly fewer spores $/ \mathrm{cm}^{2}$ than the susceptible checks 'Ashley' and 'Marketer', but significantly more than the other intermediate and resistant entries. In the field, PI 451976 performed no better than 'Ashley' in terms of preventing sporulation. Because all of the intermediate cucumbers seemed to maintain their leaves, i.e., stay green, longer than the susceptible cultivars, there was still a potential benefit from PI451976. One interesting note was that the resistance in PI 288238 was dramatically better than in PI 451976, though both are apparently selections from the same Japanese cultivar, 'Yomaki'. Selections from 'Yomaki' were made for mildew resistance at Cairo University in Egypt, with additional selection at Cornell University to develop PI 288238 (Jahn et al., 2002; Munger, 1988).

Mildew reproduction was considerably lower in the field than in the greenhouse on all cucumbers tested, including the susceptible checks. Powdery mildew was barely visible on the intermediate accessions and was not visible on the resistant accessions at any time during the field season. Weekly field spore counts for the susceptible lines 'Marketer' and 'Ashley' averaged 14,400 and 14,600 spores $/ \mathrm{cm}^{2}$, respectively with a range of 6,000 to 23,000 spores $/ \mathrm{cm}^{2}$ (data not shown). By contrast, the 26-d GH averages for 'Marketer' and 'Ashley' were $>90,000$ spores $/ \mathrm{cm}^{2}$ (Table 2). For the resistant PIs (197088, 288238, 321006, and 390258), the weekly field spore counts never exceeded the range from zero to $1300 \mathrm{spores} / \mathrm{cm}^{2}$ (data not shown). As expected, the spore counts from the intermediate accessions fell between the resistant and susceptible accessions in the field, but intermediate resistance seemed to be adequate for season-long mildew protection.

The quantitative estimates of mildew levels from washed leaf disks were effective for ranking accessions in this study. In general, the 19-d GH counts seemed to be a bit too soon to be optimal, while the 26-d GH counts seemed to give a better measure of the maximum spore load allowed by an accession. The reduced mildew spore counts in the field might be influenced in part by environmental factors such as wind, rain, humidity, and high temperatures. Yarwood (1957), in a review of powdery mildew pathosystems, noted that high temperature was the one factor consistently correlated with reduced mildew growth on many plants. More evidence for a temperature effect came when Munger (1979) noted that moderately resistant cucumbers grown at greenhouse temperatures of 15 to $21{ }^{\circ} \mathrm{C}$ seemed to be more susceptible than the same varieties grown at 21 to $27^{\circ} \mathrm{C}$.
This finding was supported by Morishita et al. (2003), who showed that some varieties, such as Natsufushinari, were resistant at 25 to 30 ${ }^{\circ} \mathrm{C}$, but susceptible at 15 to $20^{\circ} \mathrm{C}$. Resistance in other types, such as PI 197088, was independent of temperature and thought to be due to more than one resistance gene. Morishita et al. (2003) recommended that evaluations be conducted at both 20 and $26^{\circ} \mathrm{C}$ to differentiate cultivar reactions. Because our evaluations were conducted at fairly constant temperatures of 25 ${ }^{\circ} \mathrm{C}$ day and $22{ }^{\circ} \mathrm{C}$ night, some of the accessions identified as intermediate or resistant may turn out to be more susceptible below $20^{\circ} \mathrm{C}$. It would be interesting to compare the resistance of the intermediate and resistant accessions identified in this study at both high and low temperatures. Such work could identify potentially useful sources of powdery mildew resistance and help determine if the temperature effect is generally true for all cucumbers.

\section{Conclusions}

The results of our evaluations clearly demonstrated that there are significant and valuable sources of powdery mildew resistance in the NPGS cucumber germplasm collection. Many of the resistant accessions are non-uniform, containing mixtures of mildew reaction types. However, selections could be made to improve or stabilize resistance. Most of the resistance is found in accessions of Asian origin, some of which are actually highly selected cultivars with resistance to multiple diseases. Such germplasm potentially provides a ready source of mildew resistance without the detrimental genes often associated with less developed germplasm. Resistance to cucumber mosaic virus, downy mildew and anthracnose has previously been noted from Asian germplasm (Jahn et al., 2002; Peterson, 1975) and additional disease resistance may be found by focusing future evaluations on this material. Staub et al. (1997, 1999) compared the genetic variability (isozyme profiles) in cucumbers from a 1992 U.S.-India expedition (Staub et al., 1997) and from 1994 and 1996 U.S.-China collaborations (Staub et al., 1999) with genetic variability in earlier NPGS cucumber accessions. They concluded that the newer collections resulted in a distinct broadening of available genetic diversity. Furthermore, they concluded that the Indian and Chinese germplasm represented some of the most diverse genetic variation available in the NPGS collection (Staub et al., 1997, 1999) and recommended focusing future cucumber collections on India and China, as it is unlikely that the entire range of variability has been collected and conserved. In this study, we tested all of the accessions from the 1992 India collection, but relatively few of the 1994 and 1996 accessions from China because adequate seed supplies were not yet available. The recently added Chinese germplasm would be good candidates for future powdery mildew resistance evaluations as well as resistance to other diseases.

\section{Literature Cited}

Ballantyne, B. 1975. Powdery mildew on Cucurbitaceae: Identity, distribution, host range and sources of resis- tance. Proc. Linn. Soc. N.S.W. 99:100-120.

Barnes, W.C. and W.M. Epps. 1956. Powdery mildew resistance in South Carolina cucumbers. Plant Dis. Rptr. 40:1093.

Boesewinkel, H.J. 1980. The morphology of the imperfect states of powdery mildews (Erysiphaceae). The Botanical Rev. 46:167-224.

Clark, R.L. 1975. Powdery mildew resistance in plant introductions of cucumber in Iowa. Plant Dis. Rptr. 59:1024-1028.

Clark, R.L., M.P. Widrlechner, K.R. Reitsma, and C.C. Block. 1991. Cucurbit germplasm at the North Central Regional Plant Introduction Station. HortScience 26:326, 450-451.

Gomez, K.A. and A.A. Gomez. 1984. Statistical Procedures for agricultural research. 2nd ed. Wiley, New York.

Hosoya, K., M. Kuzuya, T. Murakami, K. Kato, K. Narisawa, and H. Ezura. 2000. Impact of resistant melon cultivars on Sphaerotheca fuliginea. Plant Breeding 119:286-288.

Jahn, M., H.M. Munger, and J.D. McCreight. 2002. Breeding cucurbit crops for powdery mildew resistance, p. 239-248. In: R.R. Belanger, W.R. Bushnell, A.J. Dik, and T.L.W.Carver(eds.). The powdery mildews, A comprehensive treatise. The Amer. Phytopathol. Soc., St. Paul, Minn.

Kable, P.F. and B.J. Ballantyne. 1963. Observations on the cucurbit powdery mildew in the Ithaca district. Plant Dis. Rptr. 47:482.

Kooistra, E. 1968. Powdery mildew resistance in cucumber. Euphytica 17:236-244.

Leppik, E.E. 1966. Searching gene centers of the genus Cucumis through host-parasite relationship. Euphytica 15:323-328.

McCreight, J.D., M. Pitrat, C.E. Thomas, A.N. Kishaba, and G.W. Bohn. 1987. Powdery mildew resistance genes in muskmelon. J. Amer. Hort. Sci. 112:156-160.

Morishita, M., K. Sugiyama, T. Saito, and Y. Sakata. 2003. Powdery mildew resistance in cucumber. Japan Agr. Res. Qrtly. 37:7-14.

Munger, H.M. 1979. The influence of temperature on powdery mildew resistance in cucumber. Cucurb. Genet. Coop. Rpt. 2:9-10.

Munger, H.M. 1988. Improving the level of powdery mildew resistance in cucumber. Cucurb. Genet. Coop. Rpt. 11:22.

Munger,H.M.,A. Morales, and S. Omara. 1979. Dominant genes for resistance to powdery mildew in cucumber. Cucurb. Genet. Coop. Rpt. 2:10

Peterson, C.E. 1975. Plant introductions in the improvement of vegetable cultivars. HortScience 10:575-579.

Pitrat, M., C. Dogimont, and M. Bardin. 1998. Resistance to fungal diseases of foliage in melon, p. 167-173. In: J.D. McCreight (ed.). Cucurbitaceae '98: Evaluation and enhancement of cucurbit germplasm. ASHS Press, Alexandria, Va.

Shanmugasundaram, S., P.H. Williams, and C.E.Peterson. 1971. Inheritance of resistance to powdery mildew in cucumber. Phytopathology 61:1218-1221.

Smith, P.G. 1948. Powdery mildew resistance in cucumber. Phytopathology 38:1027-1028.

Staub, J.E., F.C. Serquen, T. Horejsi, and J. Chen. 1999. Genetic diversity in cucumber (Cucumis sativus L.) IV.An evaluation of Chinese germplasm. Genet. Res. Crop Evol. 46:297-310.

Staub, J.E., F.C. Serquen, and J.D. McCreight. 1997 Genetic diversity in cucumber (Cucumis sativus L.) III. An evaluation of Indian germplasm. Genet. Res. Crop Evol. 44:315-326.

Walters, T.W. 1989. Historical overview on domesticated plants in China with special emphasis on the Cucurbitaceae. Econ. Bot. 43:297-313.

Whitaker, T.W. and G.N. Davis. 1962.Cucurbits: Botany, cultivation and utilization. Interscience, New York.

Yarwood, C.E. 1957. Powdery mildews. Bot. Rev. 23:235-300.

Zijlstra, S. and S.P.C. Groot. 1992. Search for novel genes for resistance to powdery mildew (Sphaerotheca fuliginae[sic]) in cucumber (Cucumis sativus). Euphytica. 64:31-37. 